\title{
Video Article \\ Ultra-long Read Sequencing for Whole Genomic DNA Analysis
}

\author{
Liang Gong ${ }^{1}$, Chee-Hong Wong ${ }^{1}$, Jennifer Idol ${ }^{1}$, Chew Yee Ngan $^{1}$, Chia-Lin Wei ${ }^{1}$ \\ ${ }^{1}$ Genome Technologies, Jackson Laboratory for Genomic Medicine
}

Correspondence to: Chia-Lin Wei at Chia-lin.Wei@jax.org

URL: https://www.jove.com/video/58954

DOI: doi:10.3791/58954

Keywords: Bioengineering, Issue 145, Nanopore DNA sequencing, ultra-long reads, third-generation DNA sequencing, whole genome sequence analysis, high molecular weight DNA extraction, tagmentation based DNA library construction

Date Published: 3/15/2019

Citation: Gong, L., Wong, C.H., Idol, J., Ngan, C.Y., Wei, C.L. Ultra-long Read Sequencing for Whole Genomic DNA Analysis. J. Vis. Exp. (145), e58954, doi:10.3791/58954 (2019).

\section{Abstract}

Third generation single-molecule DNA sequencing technologies offer significantly longer read length that can facilitate the assembly of complex genomes and analysis of complex structural variants. Nanopore platforms perform single-molecule sequencing by directly measuring the current changes mediated by DNA passage through the pores and can generate hundreds of kilobase (kb) reads with minimal capital cost. This platform has been adopted by many researchers for a variety of applications. Achieving longer sequencing read lengths is the most critical factor to leverage the value of nanopore sequencing platforms. To generate ultra-long reads, special consideration is required to avoid DNA breakages and gain efficiency to generate productive sequencing templates. Here, we provide the detailed protocol of ultra-long DNA sequencing including high molecular weight (HMW) DNA extraction from fresh or frozen cells, library construction by mechanical shearing or transposase fragmentation, and sequencing on a nanopore device. From 20-25 $\mu \mathrm{g}$ of HMW DNA, the method can achieve N50 read length of $50-70 \mathrm{~kb}$ with mechanical shearing and N50 of 90-100 kb read length with transposase mediated fragmentation. The protocol can be applied to DNA extracted from mammalian cells to perform whole genome sequencing for the detection of structural variants and genome assembly. Additional improvements on the DNA extraction and enzymatic reactions will further increase the read length and expand its utility.

\section{Video Link}

The video component of this article can be found at https://www.jove.com/video/58954/

\section{Introduction}

Over the past decade, massively parallel and highly accurate second-generation high-throughput sequencing technologies have driven an explosion of biomedical discovery and technological innovation ${ }^{1,2,3}$. Despite the technical advances, the short-read data generated by the second-generation platforms are ineffective in resolving complex genomic regions and are limited in the detection of genomic structural variants (SVs), which play important roles in human evolution and diseases ${ }^{4,5}$. Furthermore, short-read data are unable to resolve repeat variation and are unsuitable for discerning haplotype phasing of genetic variants ${ }^{6}$.

Recent progress in single-molecule sequencing offers significantly longer read length, which can facilitate the detection of the full spectrum of $\mathrm{SVs}^{7,8,9}$, and offers accurate and complete assembly of complex microbial and mammalian genomes ${ }^{6,10}$. The nanopore platform performs singlemolecule sequencing by directly measuring the current changes mediated by DNA passage through the pores ${ }^{11,12,13}$. Unlike any existing DNA sequencing chemistry, nanopore sequencing can generate long (tens to thousands of kilobases) reads in real-time without relying on polymerase kinetics or artificial amplification of the DNA sample. Therefore, nanopore long-read sequencing (NLR-seq) holds great promise for generating ultra-long read lengths well beyond $100 \mathrm{~kb}$, which would greatly advance genomic and biomedical analyses ${ }^{14}$, particularly in the low-complexity or repeat-rich regions of the genomes ${ }^{15}$.

The unique feature of nanopore sequencing is its potential to generate long reads without a theoretical length limitation. Therefore, the read length is dependent on the physical length of the DNA which is directly affected by the DNA integrity and sequencing template quality. Moreover, depending on the extent of manipulation and the number of steps involved, such as pipetting forces and extraction conditions, the quality of the DNA is highly variable. Therefore, it is challenging for one to yield long reads by just applying the standard DNA extraction protocols and manufacturer's supplied library construction methods. Toward this end, we have developed a robust method to generate ultra-long read (hundreds of kilobases) sequencing data starting from harvested cell pellets. We adopted multiple improvements in the DNA extraction and library preparation procedures. We streamlined the protocol to exclude unnecessary procedures that cause DNA degradation and damages. This protocol is composed of high molecular weight (HMW) DNA extraction, ultra-long DNA library construction, and sequencing on a nanopore platform. For a well-trained molecular biologist, it typically takes $6 \mathrm{~h}$ from cell harvesting to the completion of HMW DNA extraction, 90 min or 8 $\mathrm{h}$ for library construction depending on the shearing method, and up to a further $48 \mathrm{~h}$ for DNA sequencing. The use of the protocol will empower the genomics community to improve our understanding of genome complexity and gain new insight into genome variation in human diseases. 


\section{Protocol}

NOTE: The NLR-seq protocol consists of three consecutive steps: 1) extraction of high-molecular weight (HMW) genomic DNA; 2) ultra-long DNA library construction, which includes fragmentation of the HMW DNA into the desired sizes and ligation of sequencing adapters to the DNA ends; and 3) loading of the adapter-ligated DNA onto the arrays of nanopores (Figure 1).

\section{HMW DNA extraction}

1. Reagent setup. Make $1 \times$ phosphate buffered saline (PBS) buffer $(1,000 \mathrm{~mL})$ by adding $100 \mathrm{~mL}$ of PBS $(10 \mathrm{x})$ to $900 \mathrm{~mL}$ of water and mix well. Make lysis buffer $(50 \mathrm{~mL})$ by adding $43.5 \mathrm{~mL}$ of water to a $50 \mathrm{~mL}$ tube. Add $500 \mu \mathrm{L}$ of Tris $(1 \mathrm{M}, \mathrm{pH} 8.0), 1 \mathrm{~mL}$ of sodium chloride (NaCl) $(5$ M), $2.5 \mathrm{~mL}$ of ethylenediaminetetraacetic acid (EDTA) $(0.5 \mathrm{M}, \mathrm{pH} 8.0)$ and $2.5 \mathrm{~mL}$ of sodium dodecyl sulfate (SDS) $(10 \%$, wt/vol) to the tube and mix well.

NOTE: This PBS buffer can be stored at $4{ }^{\circ} \mathrm{C}$ for up to 6 months. The premade lysis buffer can be stored at RT for up to 2 months.

2. Check the cell mortality and count the cells. Ensure that the live ratio is $>85 \%$ and the total cell number is $30 \times 10^{6}$.

NOTE: The cells used in this protocol are from the HG00733 cell line, a human lymphoblastoid cell line of Puerto Rican origin widely used in the 1000 Genome consortium for structural variation analysis (see table of materials for ordering information), which belongs to International Genome Sample Resource.

3. Collect the cells by centrifuging at $200 \times g$ for $5 \mathrm{~min}$ at RT. Discard the medium and resuspend the cell pellet $\left(30 \times 10^{6} \mathrm{cells}\right)$ with $5 \mathrm{~mL}$ of $1 \mathrm{x}$ PBS buffer. Centrifuge again at $200 \times g$ for $5 \mathrm{~min}$ at RT and discard the supernatant.

NOTE: $25-35 \times 10^{6}$ of cells are acceptable for this approach. Further variation in the amount of cells used will need further optimization. The cell pellet can be stored at $-80^{\circ} \mathrm{C}$ for up to 6 months.

4. Resuspend the cell pellet in $200 \mu \mathrm{L}$ of $1 \times$ PBS buffer. If using a frozen cell pellet, wash with $5 \mathrm{~mL}$ of $1 \times$ PBS buffer. Centrifuge the solution at $200 \times g$ for 5 min at RT, discard the supernatant and resuspend the cells in $200 \mu \mathrm{L}$ of $1 \times$ PBS buffer.

5. Prepare $10 \mathrm{~mL}$ of lysis buffer in a $50 \mathrm{~mL}$ tube. Add the $200 \mu \mathrm{L}$ cell suspension to the lysis buffer and vortex at the highest speed for $3 \mathrm{~s}$. Incubate the solution at $37^{\circ} \mathrm{C}$ for $1 \mathrm{~h}$.

6. Add $2 \mu \mathrm{L}$ of RNase $\mathrm{A}(100 \mathrm{mg} / \mathrm{mL})$ to the lysate. Gently rotate the $50 \mathrm{~mL}$ tube to mix the sample. Incubate the solution at $37^{\circ} \mathrm{C}$ for $1 \mathrm{~h}$.

7. Add $50 \mu \mathrm{L}$ proteinase $\mathrm{K}(20 \mathrm{mg} / \mathrm{mL})$ to the lysate. Gently rotate the $50 \mathrm{~mL}$ tube to mix the sample. Incubate the solution at $50{ }^{\circ} \mathrm{C}$ for $2 \mathrm{~h}$. During incubation, gently mix the sample every $30 \mathrm{~min}$.

8. Remove the $50 \mathrm{~mL}$ tube from $50{ }^{\circ} \mathrm{C}$ and let stand at RT for $5 \mathrm{~min}$.

9. Add $10 \mathrm{~mL}$ of the phenol layer of phenol:chloroform:isoamyl alcohol (25:24:1, vol/vol/vol) to the lysate and rotate the tube on a rotator mixer (see Table of Materials) at RT in a fume hood at $20 \mathrm{rpm}$ for $10 \mathrm{~min}$. Wrap the tube cap with parafilm to prevent leakage during rotation.

10. Prepare two $50 \mathrm{~mL}$ gel tubes (see Table of Materials) by centrifuging at $1,500 \times g$ for 2 min at RT. NOTE: The gel forms a stable barrier between the nucleic acid-containing aqueous phase and the organic solvent.

11. Pour the sample/phenol solution into one of the prepared $50 \mathrm{~mL}$ gel tubes from Step 1.10 . Centrifuge the solution at $3,000 \times g$ for 10 min at RT.

12. Pour the supernatant into a new $50 \mathrm{~mL}$ tube. Add $10 \mathrm{~mL}$ of the phenol layer of phenol:chloroform:isoamyl alcohol (25:24:1, vol/vol/vol) and rotate the tube on a rotator mixer at $\mathrm{RT}$ in a fume hood at $20 \mathrm{rpm}$ for $10 \mathrm{~min}$.

13. Repeat step 1.11 once with the second prepared gel tube.

14. Pour the supernatant into a new $50 \mathrm{~mL}$ tube. Add $25 \mathrm{~mL}$ of ice-cold $100 \%$ ethanol and gently rotate the tube by hand until the DNA precipitates (Figure 2).

NOTE: The precipitation approach helps to stabilize the HMW DNA.

15. Bend a $20 \mu \mathrm{L}$ tip to make a hook. Carefully take out the HMW DNA with the hook and let the liquid drop off.

16. Place the HMW DNA into a $50 \mathrm{~mL}$ tube containing $40 \mathrm{~mL}$ of $70 \%$ ethanol. Wash the DNA by gently inverting the tube 3 times.

17. Repeat step 1.15 once to collect DNA from the $70 \%$ ethanol tube.

18. Place the HMW DNA into a $2 \mathrm{~mL}$ tube containing $1.8 \mathrm{~mL}$ of $70 \%$ ethanol.

19. Centrifuge the washed HMW DNA at $10,000 \times g$ for $3 s$ at RT. Remove as much of the residual ethanol as possible by pipetting. NOTE: Do not disturb the DNA pellet when pipetting the residual ethanol.

20. Incubate the $2 \mathrm{~mL}$ tube at $37^{\circ} \mathrm{C}$ for $10 \mathrm{~min}$ with the lid open to dry the sample.

1. If continuing with step 2.1 (with mechanical shearing and $1 \mathrm{D}$ Ligation Sequencing Kit), add $1 \mathrm{~mL}$ of TE (10 mM Tris and $1 \mathrm{mM}$ EDTA, $\mathrm{pH} 8.0$ ) to the $2 \mathrm{~mL}$ tube.

2. If continuing with Step 2.2 (with transposase-based fragmentation and Rapid Sequencing Kit), add $200 \mu \mathrm{L}$ of $10 \mathrm{mM}$ Tris (pH 8.0 ) with $0.02 \%$ Triton X-100

NOTE: Do not disturb the DNA pellet. Letting the tube stand at $4{ }^{\circ} \mathrm{C}$ in dark for $48 \mathrm{~h}$ will help the sample fully resuspend. The HMW DNA can be stored at $4{ }^{\circ} \mathrm{C}$ for up to 2 weeks. Longer storage time or other storage conditions may introduce more short fragments.

\section{Ultra-long DNA library construction}

NOTE: There are two ways to construct the ultra-long DNA libraries based on two different shearing methods coupled with nanopore sequencing kits. A mechanical shearing-based library produces data with an N50 of 50-70 kb, taking about $8 \mathrm{~h}$ for the library construction. A transposase fragmentation-based library produces an N50 of 90-100 kb data, taking only 90 min for the library construction. The mechanical shearing protocol gives higher yield from the same DNA input using identical versions of sequencing adapter and quality of nanopore flow cells.

1. Mechanical shearing-based library construction

1. Thaw and mix the reagents from the ligation kit (see Table of Materials). Thaw FFPE DNA repair buffer and end repair/dA-tailing buffer on ice, then vortex and spin down to mix. Thaw adapter mix (AMX) and adapter bead binding buffer (ABB) on ice, then pipette and spin 
down to mix. Thaw running buffer with fuel mix (RBF) and elution buffer (ELB) at RT, then vortex and spin down to mix. Thaw library loading beads (LLB) at RT and pipette to mix before use.

1. Once thawed, keep all kit components on ice. Take out the enzymes only when needed. Bring the magnetic beads to RT for use. NOTE: For recommendations on the magnetic beads to use see the table of materials.

2. Check the quality and quantity of the HMW DNA from step 1.21.1. Pipette out $20 \mu \mathrm{L}$ of DNA into new $1.5 \mathrm{~mL}$ tubes from three different locations in the HMW DNA tube using P200 wide bore tips. Take $1 \mu \mathrm{L}$ from the three aliquots to detect the concentration using a fluorometer and the quality using a UV reading. Check multiple times to confirm the results.

NOTE: The expected results are shown in Figure 3A. The $\mathrm{OD}_{260 / 280}$ value is approximately 1.9 and the $O \mathrm{D}_{260 / 230}$ value is approximately 2.3 .

3. Transfer the remaining $940 \mu \mathrm{L}$ of HMW DNA into a $50 \mathrm{~mL}$ tube cap with a P1000 wide bore tip.

4. Aspirate all DNA into a $1 \mathrm{~mL}$ syringe without the needle.

5. Put the $27 \mathrm{G}$ needle onto the syringe and eject all DNA into the cap gently and slowly $(\sim 10 \mathrm{~s})$. Take off the $27 \mathrm{G}$ needle from the syringe.

6. Repeat steps 2.1.4 and 2.1.5 for 29 times for a total of 30 passes through the needle.

NOTE: The sheared HMW DNA can be stored at $4{ }^{\circ} \mathrm{C}$ in the dark for up to $24 \mathrm{~h}$. Quality control (QC) is highly recommended by pulsedfield gel electrophoresis, but it is costly and time consuming. If performing QC on an automated pulse field gel electrophoresis machine use a $5-150 \mathrm{~kb}$ protocol for a $20 \mathrm{~h}$ run. The expected results are shown in Figure 4.

7. Prepare the DNA repair reaction in a $0.2 \mathrm{~mL}$ tube by adding $100 \mu \mathrm{L}$ of sheared HMW DNA (20 $\mu \mathrm{g}), 15 \mu \mathrm{L}$ of FFPE DNA repair buffer, $12 \mu \mathrm{L}$ of FFPE DNA repair mix, and $16 \mu \mathrm{L}$ of nuclease-free water. Mix the reaction by flicking gently 6 times and spin down to remove bubbles.

8. Incubate the reaction at $20^{\circ} \mathrm{C}$ for $60 \mathrm{~min}$. Transfer the sample into a new $1.5 \mathrm{~mL}$ tube with a P200 wide bore tip.

9. Resuspend the magnetic beads by pipetting or vortexing. Add $143 \mu \mathrm{L}$ beads $(1 \mathrm{x})$ to the DNA repair reaction and mix gently by flicking the tube 6 times. Rotate the tube on a rotator mixer at RT at $20 \mathrm{rpm}$ for $30 \mathrm{~min}$.

10. Spin down the sample at $1,000 \times g$ for $2 \mathrm{~s}$ at RT. Place the tube on a magnetic rack for $10 \mathrm{~min}$. Keep the tube on the magnetic rack and discard the supernatant.

11. Keeping the tube on the magnetic rack, add $400 \mu \mathrm{L}$ of freshly prepared $70 \%$ ethanol without disturbing the pellet. Remove the $70 \%$ ethanol after $30 \mathrm{~s}$.

12. Repeat step 2.1 .11 once.

13. Spin down the sample at $1,000 \times g$ for $2 \mathrm{~s}$ at RT. Place the tube back on the magnetic rack. Remove any residual ethanol and air dry for $30 \mathrm{~s}$. Do not over dry the pellet.

14. Remove the tube from the magnetic rack and add $103 \mu \mathrm{L}$ of TE (10 mM Tris and $1 \mathrm{mM}$ EDTA, pH 8.0). Gently flick the tube to ensure that beads are covered in the buffer, and incubate on a rotator mixer at RT for $30 \mathrm{~min}$. Gently flick the tube every $5 \mathrm{~min}$ to aid resuspension of the pellet.

15. Pellet the beads on the magnetic rack for at least $10 \mathrm{~min}$. Transfer $100 \mu \mathrm{L}$ of eluate with a P200 wide bore tip into a $0.2 \mathrm{~mL}$ tube.

16. Prepare the end repair and dA-tailing reaction in a $0.2 \mathrm{~mL}$ tube by adding $100 \mu \mathrm{L}$ of repaired HMW DNA, $14 \mu \mathrm{L}$ of end repair/dA-tailing buffer and $7 \mu \mathrm{L}$ of end repair/dA-tailing mix. Mix the reaction by flicking gently 6 times, and spin down to remove bubbles.

17. Incubate the reaction at $20^{\circ} \mathrm{C}$ for $60 \mathrm{~min}$ followed by $65^{\circ} \mathrm{C}$ for $20 \mathrm{~min}$, and then hold at $22^{\circ} \mathrm{C}$. Transfer the sample into a new $1.5 \mathrm{~mL}$ tube using a P200 wide bore tip.

18. Resuspend the magnetic beads by pipetting or vortexing. Add $48 \mu \mathrm{L}$ of beads $(0.4 \mathrm{x})$ to the end repair/dA-tailing reaction and mix gently by flicking the tube 6 times. Rotate the tube on a rotator mixer at RT at $20 \mathrm{rpm}$ for $30 \mathrm{~min}$.

19. Repeat steps 2.1.10-2.1.13 once.

20. Remove the tube from the magnetic rack and add $33 \mu \mathrm{L}$ of TE (10 mM Tris and $1 \mathrm{mM}$ EDTA, pH 8.0). Gently flick the tube to ensure that beads are covered in the buffer, and incubate on a rotator mixer at RT for $30 \mathrm{~min}$. Gently flick the tube every $5 \mathrm{~min}$ to aid resuspension of the pellet.

21. Pellet the beads on the magnetic rack for at least $10 \mathrm{~min}$. Transfer $30 \mu \mathrm{L}$ of eluate with a P200 wide bore tip into a new $1.5 \mathrm{~mL}$ tube. Take the extra 1-2 $\mu \mathrm{L}$ to detect the concentration using a fluorometer.

NOTE: Recovery of 5-6 $\mu \mathrm{g}$ at this step is expected.

22. Prepare the ligation reaction in the $1.5 \mathrm{~mL}$ sample tube by adding $30 \mu \mathrm{L}$ of end-repaired HMW DNA, $20 \mu \mathrm{L}$ of adapter mix (AMX 1D), and $50 \mu \mathrm{L}$ of blunt/TA ligation master mix. Mix the reaction by flicking gently 6 times between each sequential addition and spin down to remove bubbles.

23. Incubate the reaction at RT for $60 \mathrm{~min}$.

24. Resuspend the magnetic beads by pipetting or vortexing. Add $40 \mu \mathrm{L}$ beads $(0.4 \mathrm{x})$ to the ligation reaction and mix gently by flicking the tube 6 times. Rotate the tube on a rotator mixer at RT at $20 \mathrm{rpm}$ for $30 \mathrm{~min}$.

25. Repeat step 2.1.10 once.

26. Add $400 \mu \mathrm{L}$ of adapter bead binding (ABB) buffer into the tube. Flick the tube gently 6 times to resuspend the beads. Place the tube back on the magnetic rack to separate the beads from the buffer and discard supernatant.

27. Repeat step 2.1.26 once.

28. Spin down the sample at $1,000 \times g$ for $2 s$ at RT. Place the tube back on the magnetic rack. Remove any residual buffer and air dry for $30 \mathrm{~s}$. Do not over dry the pellet.

29. Remove the tube from the magnetic rack and resuspend the pellet in $43 \mu \mathrm{L}$ of elution buffer. Gently flick the tube to ensure that beads are covered in the buffer and incubate on a rotator mixer at RT for $30 \mathrm{~min}$. Gently flick the tube every 5 min to aid resuspension of the pellet.

30. Pellet the beads on the magnetic rack for at least $10 \mathrm{~min}$. Transfer $40 \mu \mathrm{L}$ of eluate with a P200 wide bore tip into a new $1.5 \mathrm{~mL}$ tube. Take the extra 1-2 $\mu \mathrm{L}$ to detect the concentration using a fluorometer. NOTE: Recovery of $1-2 \mu \mathrm{g}$ at this step is expected. The mechanical shearing-based library is ready for loading. The library can be stored on ice for up to $2 \mathrm{~h}$ until loading for sequencing if needed.

\section{Transposase fragmentation-based library construction}


1. Thaw the reagents from the transposase kit (see Table of Materials). Thaw fragmentation mix (FRA) and rapid adapter (RAP) on ice and pipette to mix. Thaw sequencing buffer (SQB), loading beads (LB), flush buffer (FLB) and flush tether (FLT) at RT and pipette to mix. Thaw loading beads (LB) at RT and pipette to mix before use. Once thawed, keep all kit components on ice. Take out the enzymes only when needed.

2. Check the quality and quantity of the HMW DNA from step 1.21.2. Pipette out $20 \mu \mathrm{L}$ of DNA into new $1.5 \mathrm{~mL}$ tubes from three different locations in the HMW DNA tube using P200 wide bore tips. Take $1 \mu \mathrm{L}$ from the three aliquots to detect the concentration using a fluorometer and the quality using a UV reading. Check multiple times to confirm the results.

NOTE: The expected results are shown in Figure 3B. The $\mathrm{OD}_{260 / 280}$ value is approximately 1.9 and the $O D_{260 / 230}$ value is approximately 2.3 .

3. Prepare the DNA tagmentation reaction in a $0.2 \mathrm{~mL}$ tube by adding $22 \mu \mathrm{L}$ of HMW DNA, $1 \mu \mathrm{L}$ of $10 \mathrm{mM}$ Tris (pH 8.0) with $0.02 \%$ Triton $\mathrm{X}-100$ and $1 \mu \mathrm{L}$ of fragmentation mix (FRA). Mix by pipetting with a P200 wide bore tip as slowly as possible 6 times, taking care not to introduce bubbles.

4. Incubate the reaction at $30^{\circ} \mathrm{C}$ for 1 min followed by $80^{\circ} \mathrm{C}$ for $1 \mathrm{~min}$, and then hold at $4{ }^{\circ} \mathrm{C}$. Transfer the mix into a new $1.5 \mathrm{~mL}$ tube with a P200 wide bore tip and go to next step immediately.

5. Add $1 \mu \mathrm{L}$ of rapid adapter (RAP) to the $1.5 \mathrm{~mL}$ sample tube. Mix by pipetting with a P200 wide bore tip as slowly as possible 6 times, taking care not to introduce bubbles.

6. Incubate the reaction at RT for $60 \mathrm{~min}$.

NOTE: The transposase fragmentation-based library is ready for loading. The library can be stored on ice for up to $2 \mathrm{~h}$ until loading for sequencing if needed.

\section{Sequencing on the nanopore device}

1. Check the nanopore sequencing device (see Table of Materials). Make sure both the software and hardware are working and there is enough storage space.

2. Check the flow cell. Open a new flow cell and insert the flow cell into the nanopore device. Check the box of the location the flow cell was inserted into (X1-X5). Select the correct flow cell type. Click on the Check Flow Cells workflow. Click on the Start Test button to start the flow cell QC analysis.

NOTE: If the reported total active pore number is less than 800 , use a different new flow cell for sequencing.

3. Prepare the priming buffer. For a mechanical shearing-based library, add $576 \mu \mathrm{L}$ of running buffer with fuel mix (RBF) and $624 \mu \mathrm{L}$ of nuclease-free water into a $1.5 \mathrm{~mL}$ tube. Vortex and spin down to mix the priming buffer. For a transposase fragmentation-based library, add $30 \mu \mathrm{L}$ of flush tether (FLT) to the tube of flush buffer (FLB). Vortex and spin down to mix the priming buffer.

4. On the flow cell, move the priming port cover clockwise to expose the priming port.

5. Set a P1000 pipette to $100 \mu \mathrm{L}$ and insert the tip into the priming port. Draw back a small volume of buffer (less than $30 \mu \mathrm{L}$ ) to remove any bubbles from the flow cell. Stop pipetting once a small amount of yellow fluid enters the tip.

6. Use a P1000 pipette to load $800 \mu \mathrm{L}$ of the priming mix into the flow cell via the priming port. To avoid introducing bubbles, add $30 \mu \mathrm{L}$ of the priming mix to cover the top of the priming port first, then insert the tip into the priming port and slowly add the rest of the priming mix. Take out the tip when there is about $50 \mu \mathrm{L}$ left. Add the rest of priming mix on the top of the priming port. The fluid will go inside by itself.

7. Leave the setup to incubate for $5 \mathrm{~min}$. In the meantime, prepare the library mix in the $1.5 \mathrm{~mL}$ tube containing the library. NOTE: For a mechanical shearing-based library add $35 \mu \mathrm{L}$ of running buffer with fuel mix (RBF) to $40 \mu \mathrm{L}$ of the DNA library. For a transposase fragmentation-based library add $34 \mu \mathrm{L}$ of sequencing buffer (SQB) and $16 \mu \mathrm{L}$ of nuclease-free water to $25 \mu \mathrm{L}$ of the DNA library.

8. Open the flow cell sample port cover gently to expose the sample port. Use a P1000 pipette to add $200 \mu \mathrm{L}$ of the priming mix through the priming port into the flow cell as described in step 3.5. Make sure that the priming mix is not loaded into the flow cell through the sample port.

9. Set a P200 pipette to $80 \mu \mathrm{L}$. Mix the library gently with a wide bore tip by pipetting up and down 6 times just prior to loading.

10. Load the library mix dropwise through the sample port into the flow cell. Add each drop only after the previous drop is completely loaded into the port.

11. Put back the sample port cover gently and make sure the sample port is fully covered. Move the priming port cover anticlockwise to cover the priming port. Close the device lid.

12. Click on the New Experiment workflow. Type the library name, select the correct kit according to procedures used, and check that the settings are correct (48 $\mathrm{h}$ run, real-time base-calling $\mathrm{ON}$ ).

13. Click Start Run. After $10 \mathrm{~min}$, record the flow cell ID and the active nanopore numbers (total number and each four groups' numbers) from the run information.

14. Data analysis. Copy the data to a local computer or a cluster at any time of the sequencing or when the run is complete. Use Minimap $2^{16}$ (https://github.com/lh3/minimap2) to align the sequence data to the reference genome. Summarize the sequencing performance from the raw sequence data and the alignments by NanoPlot ${ }^{17}$ (https://github.com/wdecoster/NanoPlot).

\section{Representative Results}

The ultra-long DNA sequencing protocol applies HMW DNA for library construction. Therefore, it is critical to choose well-cultured cells with the live ratio $>85 \%$ at the cell harvesting step. The amount of cells used for DNA extraction will affect the quality and the quantity of the HMW DNA. The cell lysis does not work well if starting with too many cells. Using too few cells does not generate enough DNA for library construction because the HMW DNA precipitation is performed using gentle rotation by hand instead of high-speed centrifugation. An example of the HMW DNA after adding ice-cold $100 \%$ ethanol and rotating is shown as the white cotton-like precipitate in Figure 2.

It is important to check the quality of the input DNA before beginning the library construction. Degradation, incorrect quantification, contamination (e.g., proteins, RNAs, detergents, surfactant, and residual phenol or ethanol) and low molecular weight DNA can have a significant effect on the subsequent procedures and on the final read length. We recommend performing the $Q C$ analysis using the DNA from three different locations in the tube containing HMW DNA. From UV reading results for the HMW DNA, the $\mathrm{OD}_{260} / O D_{280}$ value is approximately 1.9 and the $\mathrm{OD}_{260} / \mathrm{OD}_{230}$ value is approximately 2.3 (Figure 3A,B). These ratio values are consistent among the three tests for a good HMW DNA sample. 
Different shearing methods requires different volumes of input DNA. The concentration of HMW DNA needs to be $>200 \mathrm{ng} / \mu \mathrm{L}$ for mechanical shearing while it needs to be $>1 \mu \mathrm{g} / \mu \mathrm{L}$ for transposase fragmentation. The concentration detected by a fluorometer is a little lower than UV reading. However, the coefficient of variation of the concentration of the same HMW DNA sample is required to be less than $15 \%$ with both the fluorometer and the UV reading assays. Mechanical shearing applies a syringe with a needle to break the HMW DNA so that the number of passes through the needle will impact the size of the sheared DNA and the final read length. It is recommended to perform size QC after needle shearing to ensure the majority of the HMW DNA is larger than $50 \mathrm{~kb}$ as illustrated in Figure 4 . In the mechanical shearing method, 30 passes generated the best sequencing results considering both the length and output.

The N50 of a mechanical shearing-based library is $50-70 \mathrm{~kb}$ while a transposase fragmentation-based library is $90-100 \mathrm{~kb}$. The results of four runs using the HG00733 cell line are shown in Table 1. All four runs have over 2,300 reads with length longer than $100 \mathrm{~kb}$. The maximum length is longer in the transposase fragmentation-based libraries ( $455 \mathrm{~kb}$ and $489 \mathrm{~kb}$ ) compared with the mechanical shearing-based libraries (348 kb and $387 \mathrm{~kb}$ ) while the latter produced more total reads, indicating a higher yield. The transposase fragmentation-based library construction has fewer steps and shorter preparation time so that it will introduce fewer short fragments. The two runs using transposase have a longer mean length $(>30 \mathrm{~kb})$ and median length $(>10 \mathrm{~kb})$. In addition, the data shows consistent high quality in all runs (mean quality score is approximately $10.0, \sim 90 \%$ base accuracy). More than $97 \%$ of the total bases were aligned to the human reference genome (hg19) using Minimap ${ }^{16}$ with the default settings. The expected size distributions of the raw reads are shown in Figure 5 . All runs have a large proportion of data above $50 \mathrm{~kb}$ while transposase fragmentation-based libraries have a higher ratio of ultra-long reads (e.g. > $100 \mathrm{~kb}$ ). This protocol has been successfully applied in multiple human cell lines (Supplementary Table 1).

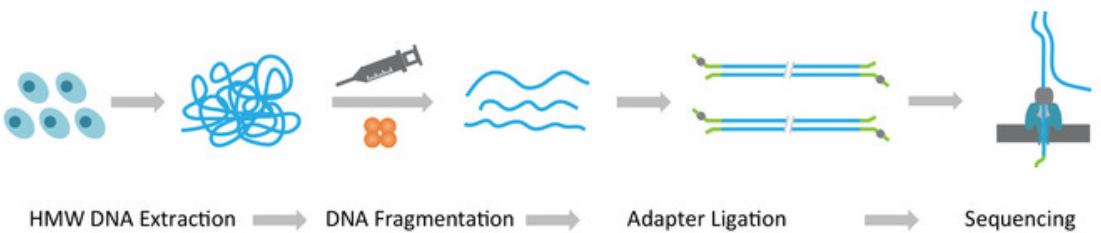

Figure 1: Schematic overview of the nanopore long-read sequencing (NLR-seq) workflow. Orange, the transposase complex. Yellowgreen, the nanopore adapter. Please click here to view a larger version of this figure. 


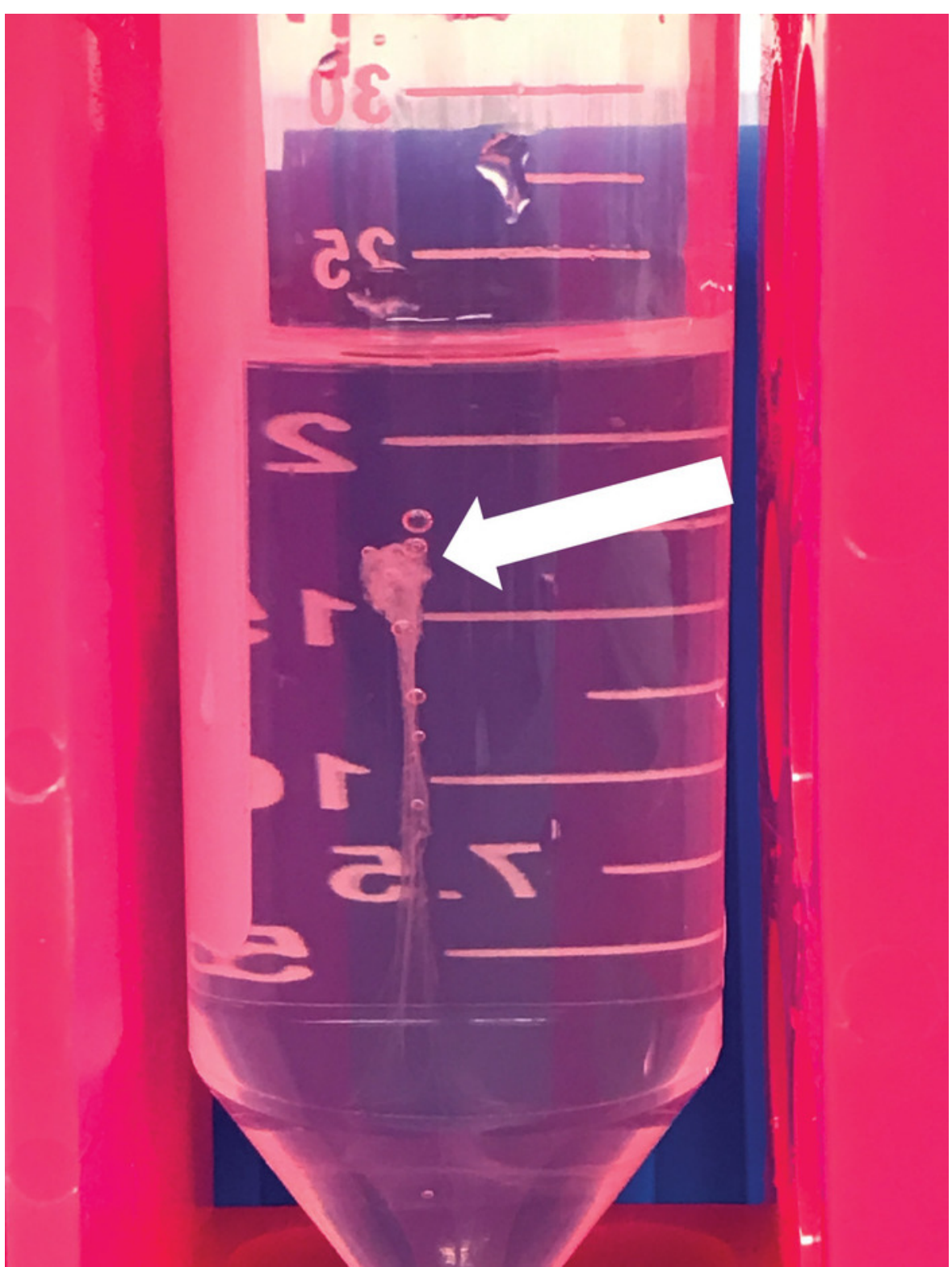

Figure 2: Representative DNA precipitation from phenol-chloroform extraction method. The white arrow indicates the HMW DNA. Please click here to view a larger version of this figure. 
A

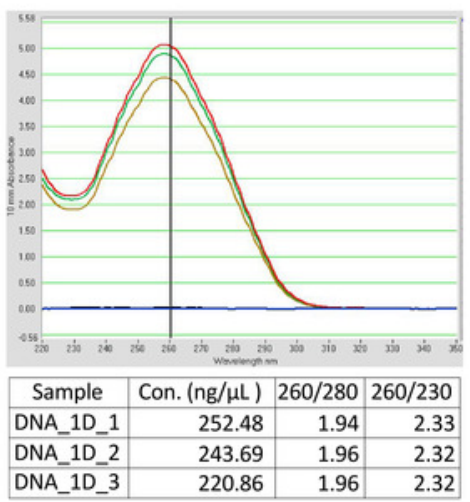

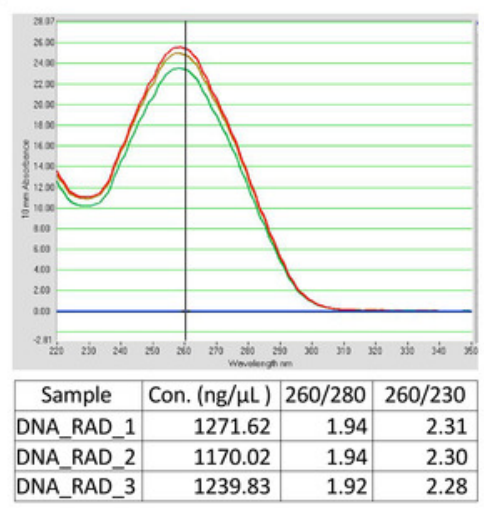

Figure 3: Example QC results of the HMW DNA from UV reading. (A) HMW DNA from step 1.21.1 ready for mechanical shearing-based library construction. (B) HMW DNA from step 1.21.2 for transposase fragmentation-based library construction. Please click here to view a larger version of this figure.

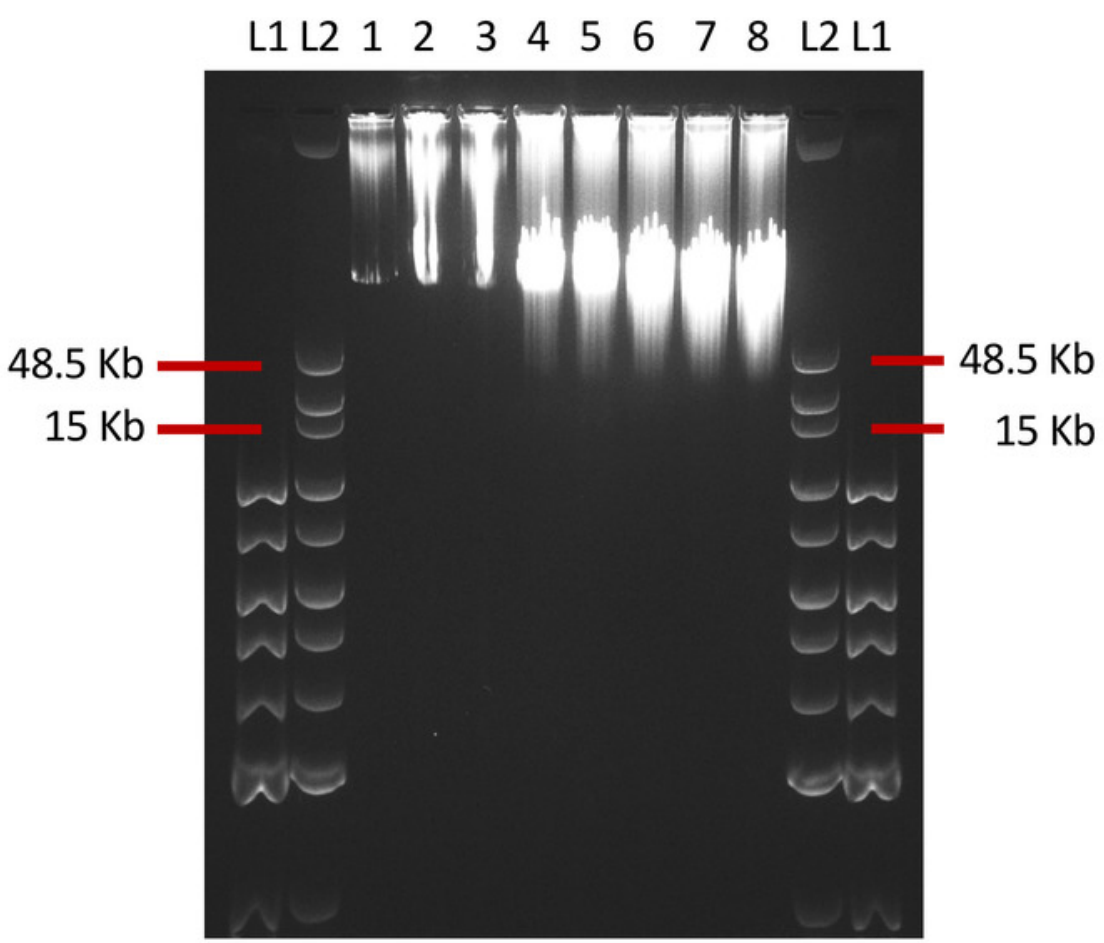

Figure 4: QC results of the needle sheared HMW DNA by pulsed-field gel electrophoresis. L1: Quick-load 1 kb DNA ladder; L2: Quickload $1 \mathrm{~kb}$ extend DNA ladder. 1-8: DNA with different passing times through the needle shearing. 1-3, no shearing; 4, 10 times; 5,20 times; 6,30 times; 7, 40 times; 8, 50 times. This QC step is optional. Please click here to view a larger version of this figure. 


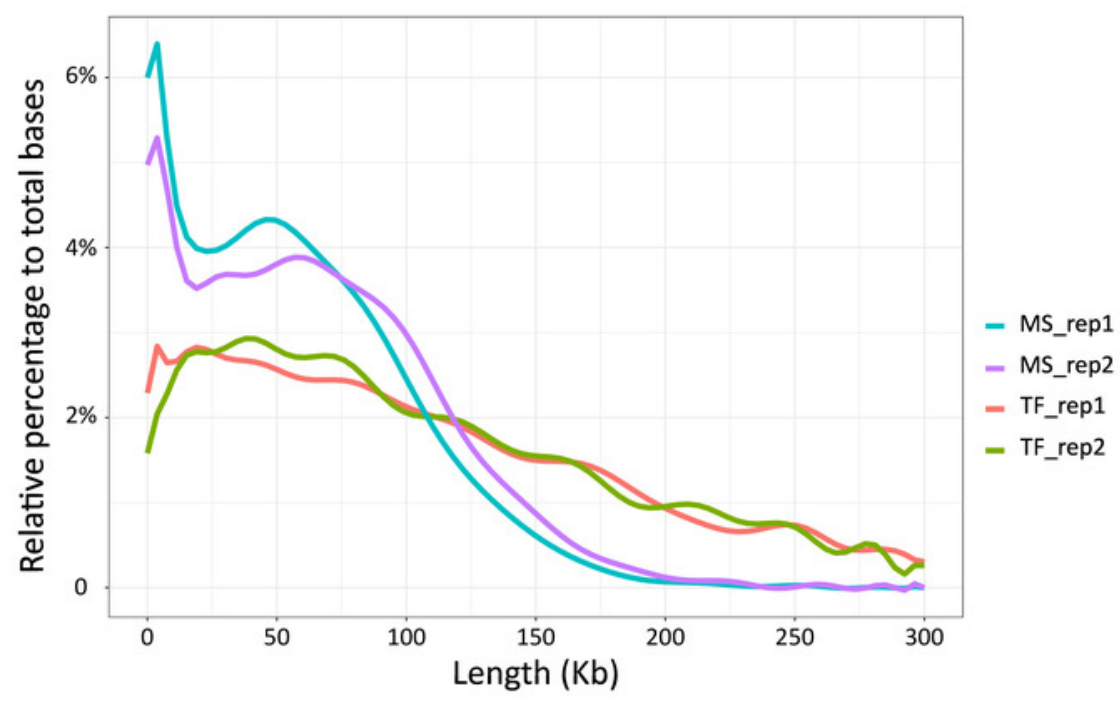

Figure 5: Expected size distributions of the nanopore ultra-long DNA libraries. MS, mechanical shearing-based libraries. TF, transposase fragmentation-based libraries. Please click here to view a larger version of this figure.

\begin{tabular}{|l|l|l|l|l|}
\hline & $\begin{array}{l}\text { Mechanical } \\
\text { shearing_rep1 }\end{array}$ & $\begin{array}{l}\text { Mechanical } \\
\text { shearing_rep2 }\end{array}$ & $\begin{array}{l}\text { Transposase } \\
\text { fragmentation_rep1 }\end{array}$ & $\begin{array}{l}\text { Transposase } \\
\text { fragmentation_rep2 }\end{array}$ \\
\hline Cell line & HG00733 & HG00733 & HG00733 & HG00733 \\
\hline N50 of the reads & 55,180 & 63,007 & 98,237 & 95,629 \\
\hline $\begin{array}{l}\text { Number of reads longer } \\
\text { than 100 Kb }\end{array}$ & 2,500 & 3,082 & 2,386 & 2,355 \\
\hline Number of total reads & 97,859 & 80,465 & 24,166 & 21,032 \\
\hline Maximum length (bp) & 348,482 & 387,113 & 454,660 & 489,426 \\
\hline Mean length (bp) & 17,861 & 20,395 & 33,528 & 38,175 \\
\hline Median length (bp) & 5,335 & 5,894 & 10,249 & 15,656 \\
\hline Mean quality of the reads & 10.0 & 10.1 & 9.9 & 10.0 \\
\hline Total bases of raw reads & $1,747,849,822$ & $1,641,058,932$ & $810,229,733$ & $802,886,304$ \\
\hline $\begin{array}{l}\text { Total bases of aligned } \\
\text { reads }\end{array}$ & $1,693,300,832$ & $1,607,975,925$ & $791,422,077$ & $778,417,627$ \\
\hline $\begin{array}{l}\text { Mapped ratio of total bases } \\
\text { (hg19, Minimap2) }\end{array}$ & $96.9 \%$ & $98.0 \%$ & $97.7 \%$ & $97.0 \%$ \\
\hline Number of active pores & $1225: 480,402,254,89$ & $1058: 480,356,176,46$ & $958: 452,328,148,30$ & $1092: 487,367,195,43$ \\
\hline
\end{tabular}

Table 1: Performance metrics summary from runs with different shearing protocols. 


\begin{tabular}{|l|l|l|}
\hline & Library $\mathbf{1}$ & Library 2 \\
\hline Cell line & K562 & GM19240 \\
\hline Cell Ordering Information & ATCC, cat. No. CCL-243 & Coriell Institute, cat. No. GM19240 \\
\hline Protocol & mechanical shearing & mechanical shearing \\
\hline N50 of the reads & 60,063 & 55,295 \\
\hline Number of total reads & 193,783 & 120,807 \\
\hline Median length (bp) & 1,843 & 4,688 \\
\hline Mean length (bp) & 9,825 & 17,408 \\
\hline Maximum length (bp) & 548,780 & 212,338 \\
\hline Total bases of raw reads & $1,903,989,686$ & $2,103,015,331$ \\
\hline Total bases of aligned reads & $1,837,350,047$ & $1,997,419,761$ \\
\hline Mapped ratio of total bases (hg19, Minimap2) & $96.6 \%$ & $95.0 \%$ \\
\hline Number of active pores & $1111: 482,371,203,55$ & $1032: 447,333,196,56$ \\
\hline
\end{tabular}

Supplementary Table 1: Summary of two NLR-seq runs using other cell lines with the mechanical shearing protocol.

\section{Discussion}

In principle, nanopore sequencing is able to generate $100 \mathrm{~kb}$ to megabase reads in length ${ }^{11,12,13}$. Four major factors will affect the performance of the sequencing run and data quality: 1) active pore numbers and the activity of the pores; 2) motor protein, which controls the speed of DNA passing through the nanopore; 3) DNA template (length, purity, quality, mass); 4) sequencing adapter ligation efficiency, which determines the useable DNA from the input sample. The first two factors depend on the version of the flow cell and the sequencing kit provided by the manufacturer. The second two factors are critical steps in this protocol (HMW DNA extraction, shearing and ligation).

This protocol requires patience and practice. The quality of HMW DNA is important for ultra-long DNA libraries ${ }^{6}$. The protocol starts with cells collected with high viability ( $>85 \%$ viable cell preferred), limiting the degraded DNA from dead cells. Any harsh process which may introduce damages to the DNA (e.g., strong disturbing, shaking, vortex, multiple pipetting, repeated freezing and thawing) should be avoided. In the design of the protocol, we omit pipetting in the entire process of DNA extraction. Wide bore tips need to be used when pipetting is necessary after the mechanical shearing during library construction and sequencing. As the nanopores are sensitive to the chemistries in the chamber buffer ${ }^{12}$, there should be as few residual contaminants (e.g., the detergents, surfactants, phenol, ethanol, proteins RNAs, etc.) as possible in the DNA. Considering the length and yield, the phenol extraction method shows the best and most reproducible results compared with multiple different extraction methods tested so far.

Despite the ability of this protocol to produce long-read sequences, several limitations still remain. First, this protocol was optimized based on the nanopore sequencing device available at time of publication; thus, it is limited to the selective nanopore-based sequencing chemistry and could be suboptimal when performed in other types of long-read sequencing devices. Second, the outcome is highly dependent on the quality of the DNA extracted from the starting material (tissues or cells). Read length will be compromised if the starting DNA is already degraded or damaged. Third, although multiple QC steps are incorporated in the protocol to check the DNA quality, the final yield and length of the reads can be affected by the flow cell and pore activity, which could be variable at this early stage of nanopore sequencing platform development.

The protocol described here uses human suspension cell line samples for DNA extraction. We have optimized the passing times in needle shearing, the ratio of HMW DNA to transposase and the ligation time to produce the described results. The protocol can be expanded in four ways. First, users can start with other cultured mammalian cells and with different amount of cells, tissues, clinical samples, or other organisms Further optimization on lysis incubation time, reaction volume and centrifugation will be needed. Second, it is hard to predict the target size for ultra-long read sequencing. If the read lengths are shorter than expected, the users can adjust the passing times in the mechanical shearingbased method or change the ratio of the HMW DNA to transposase in the transposase fragmentation-based method. Longer binding and elution time during cleanup steps are helpful because the HMW DNA is highly viscous. Third, with different nanopore sequencing devices, one can adjust the amount and volume of the DNA to meet the criteria of the sequencer. Fourth, only those DNA ligated to sequencing adapters will be sequenced. To further improve ligation efficiency, one can attempt to titrate the adapter and ligase concentrations. Modified ligation time and molecular crowding agents such as $\mathrm{PEG}^{18}$ can be applied in future. The ultra-long DNA sequencing protocol combined with $\mathrm{CRISPR}^{19,20}$ may offer an effective tool for target enrichment sequencing.

\section{Disclosures}

The authors declare that they have no competing financial interests

\section{Acknowledgments}

The authors thank Y. Zhu for her comments on the manuscript. Research reported in this publication was partially supported by the National Cancer Institute of the National Institutes of Health under Award Number P30CA034196. The content is solely the responsibility of the authors and does not necessarily represent the official views of the National Institutes of Health. 


\section{References}

1. Mardis, E. R. Next-generation sequencing platforms. Annual Review of Analytical Chemistry. 6, 287-303 (2013).

2. Goodwin, S., McPherson, J. D., McCombie, W. R. Coming of age: ten years of next-generation sequencing technologies. Nature Reviews Genetics. 17 (6), 333-351 (2016).

3. Shendure, J. et al. DNA sequencing at 40: past, present and future. Nature. 550 (7676), 345-353 (2017).

4. Alkan, C., Coe, B. P., Eichler, E. E. Genome structural variation discovery and genotyping. Nature Reviews Genetics. 12 (5), $363-376$ (2011).

5. Weischenfeldt, J., Symmons, O., Spitz, F., Korbel, J. O. Phenotypic impact of genomic structural variation: insights from and for human disease. Nature Reviews Genetics. 14 (2), 125-138 (2013).

6. Pollard, M. O., Gurdasani, D., Mentzer, A. J., Porter, T., Sandhu, M. S. Long reads: their purpose and place. Human Molecular Genetics. 27 (R2), R234-r241 (2018).

7. Cretu Stancu, M. et al. Mapping and phasing of structural variation in patient genomes using nanopore sequencing. Nature Communications. 8 (1), 1326 (2017).

8. Gong, L. et al. Picky comprehensively detects high-resolution structural variants in nanopore long reads. Nature Methods. 15 (6), $455-460$ (2018).

9. Sedlazeck, F. J. et al. Accurate detection of complex structural variations using single-molecule sequencing. Nature Methods. 15 (6), $461-468$ (2018).

10. Jain, M. et al. Nanopore sequencing and assembly of a human genome with ultra-long reads. Nature Biotechnology. 36 (4), $338-345$ (2018).

11. Jain, M. et al. Improved data analysis for the MinION nanopore sequencer. Nature Methods. 12 (4), 351-356 (2015).

12. Deamer, D., Akeson, M., Branton, D. Three decades of nanopore sequencing. Nature Biotechnology. 34 (5), $518-524$ (2016).

13. Jain, M., Olsen, H. E., Paten, B., Akeson, M. The Oxford Nanopore MinION: delivery of nanopore sequencing to the genomics community. Genome Biology. 17 (1), 239 (2016).

14. Editorial. The long view on sequencing. Nature Biotechnology. 36 (4), 287 (2018).

15. Jain, M. et al. Linear assembly of a human centromere on the Y chromosome. Nature Biotechnology. 36 (4), $321-323$ (2018).

16. Li, H. Minimap2: pairwise alignment for nucleotide sequences. Bioinformatics. 34, 3094-3100 (2018).

17. De Coster, W., D'Hert, S., Schultz, D.T., Cruts, M., Van Broeckhoven, C. NanoPack: visualizing and processing long-read sequencing data. Bioinformatics. 34, 2666-2669 (2018).

18. Akabayov, B., Akabayov, S. R., Lee, S. J., Wagner, G., Richardson, C. C. Impact of macromolecular crowding on DNA replication. Nature Communications. 4, 1615 (2013).

19. Gabrieli, T., Sharim, H., Michaeli, Y., Ebenstein, Y. Cas9-Assisted Targeting of CHromosome segments (CATCH) for targeted nanopore sequencing and optical genome mapping. bioRxiv.(2017).

20. Gabrieli, T. et al. Selective nanopore sequencing of human BRCA1 by Cas9-assisted targeting of chromosome segments (CATCH). Nucleic Acids Research. (2018). 